\title{
Implanting a mechanical valve in the pulmonary position: What's your bias?
}

\author{
Erle H. Austin III, MD
}

From the Department of Cardiovascular and Thoracic Surgery, University of Louisville, Norton Children's Hospital, Louisville, Ky.

Disclosures: Author has nothing to disclose with regard to commercial support.

Received for publication May 10, 2017; accepted for publication May 11, 2017; available ahead of print June 16, 2017.

Address for reprints: Erle H. Austin III, MD, Department of Cardiovascular and Thoracic Surgery, University of Louisville, Norton Children's Hospital, 201 Abraham Flexner Way, Suite 1200, Louisville, KY 40202 (E-mail: erle.austin@ulp.org).

J Thorac Cardiovasc Surg 2017;154:1368-70

$0022-5223 / \$ 36.00$

Copyright (c) 2017 by The American Association for Thoracic Surgery

http://dx.doi.org/10.1016/j.jtcvs.2017.05.018

Cardiovascular surgeons perform heart valve replacements on a daily basis, and each time the question comes up: Do we implant a mechanical or tissue valve? Our experience is derived primarily from replacements for the aortic and mitral positions. We all understand that neither type of valve is ideal, each with its advantages and disadvantages, and we recognize that there are conditions that favor one type or the other. When conditions such as atrial fibrillation, bleeding diathesis, desire to have a child, or medical noncompliance are not factors, it usually comes down to a discussion with the patient regarding his or her lifestyle, fears, and concerns. In the case of replacement of left-sided valves, most of us are willing to let a well-informed patient direct the choice between mechanical and tissue. Admittedly, many surgeons and practices have a bias in one direction or the other, but most will try to provide the patient with a fair appraisal of the pros and cons of the 2 types and try to sense which will be preferred by that patient. However, when it comes to replacing a pulmonary valve in a patient without a condition favoring one type over the other, many surgeons (myself included) feel obliged to recommend against a mechanical valve. The accompanying study by Pragt and colleagues ${ }^{1}$ might prompt some of those surgeons to rebalance their bias.

The earliest descriptions of placing a valve in the pulmonary position involved connecting the right ventricle to the main pulmonary artery with a valved allograft. ${ }^{2,3}$ By 1974 , experience with mechanical valves containing conduits was being reported with satisfactory early success. ${ }^{4}$ Most experience with pulmonary valve replacement has been in patients surviving complete repair of tetralogy of Fallot who present later with right ventricular failure and progressive right ventricular enlargement. In 1983, Misbach and colleagues ${ }^{5}$ reported their experience with 12 such patients in whom they performed pulmonary valve replacements; 2 of the 12 patients received mechanical valves. Concern for both the limited longevity of tissue valves and the anticoagulation requirement for mechanical valves was

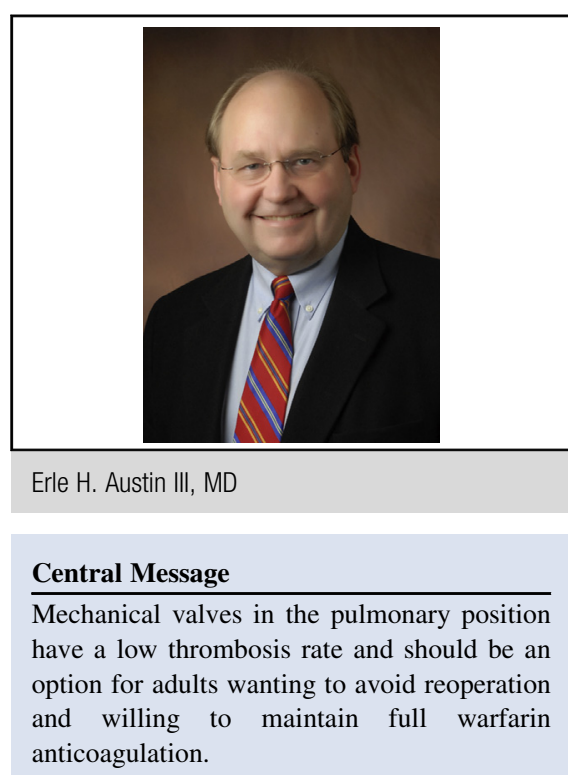

See Article page 1371. expressed in that article supporting a policy of pulmonary valve replacement in only the most symptomatic patients. By the late 1980s, a bias against mechanical valves in the pulmonary position began to develop and may be attributed to 2 separate reports in 1987 . Ilbawi and colleagues ${ }^{6}$ noted mechanical valve dysfunction in 6 of 16 patients with valves in the pulmonary position compared with 0 of 20 patients with valves on the left side. Miyamura and colleagues ${ }^{7}$ reported valve thrombosis in 2 of 5 patients with tetralogy undergoing pulmonary valve replacement with mechanical valves. It is important to recognize that in both reports the affected patients were aged less than 10 years. Those of us who care for children understand that managing anticoagulation in very young patients is a challenge, and results derived in young children may not be applicable to an adult population. Nevertheless, many of us who trained in the 1980s and early 1990s were advised to avoid mechanical valves in the pulmonary position regardless of the patient's age.

Of course, in life and in cardiac surgery, standards must be challenged from time to time to reassess their true validity. In 1998, Rosti and colleagues ${ }^{8}$ reported a small series of patients who had undergone pulmonary valve replacement with mechanical valves and demonstrated acceptable outcomes to 9 years of follow-up. The authors suggested that "a reappraisal" was indicated to determine whether 
mechanical valve replacement might be appropriate for selected patients. By 2005, additional reports began to appear in the literature. Haas and colleagues ${ }^{9}$ reported an experience of 14 patients receiving mechanical valved conduits in the pulmonary position with a follow-up to 63 months without evidence of valve failure. These patients had been selected because of older age, multiple prior operations, and current anticoagulation with demonstrated compliance. Haas and colleagues ${ }^{9}$ noted that the population of patients requiring pulmonary valve implantation was increasing, and inserting a mechanical valve offered the real potential for avoiding further operations. Joseph Dear$\mathrm{ani}^{10}$ from the Mayo Clinic provided the invited commentary for that report and indicated that the Mayo program also had an experience with placing mechanical valves in the pulmonary position: 17 adults with follow-up to 25 years without valve thrombosis. Soon, more series of mechanical pulmonary valve implantations began to appear in the literature. Significant among these reports was the experience from the University of Groningen, ${ }^{11}$ where $45 \%$ of patients aged 18 years or older requiring pulmonary valve replacement had received a mechanical valve. Before long, reports of favorable results for mechanical valve insertion in the pulmonary position began to appear from cardiac surgery centers all over the world. ${ }^{12-19}$ Recognizing similar results at other centers, the group from Groningen sought to gather data from the 7 sites with the largest published experiences to assess outcomes in a larger set of patients. This brings us to the study at hand. ${ }^{1}$

Pragt and colleagues ${ }^{1}$ were able to achieve cooperation and agreement from all 7 centers to provide data updated from the time of their original publications. This resulted in a multicenter database that included 364 patients undergoing an initial mechanical pulmonary valve insertion from 1965 to 2014. Combining these data permitted a retrospective time-related analysis extending as far back as 33 years. The patients were primarily adults with a mean age of 27 years. The median labeled size of the mechanical valve implanted was $25 \mathrm{~mm}$. The median follow-up was only 4.26 years, influenced by the large number of Tehran patients whose mean follow-up was 2.3 years. Within the entire cohort, however, there were 152 patients followed for more than 5 years and 58 patients followed for more than 10 years. The primary end point chosen for this study was thrombosis of the implanted mechanical valve. Secondary end points were reoperation, death, and thrombolysis. In terms of the primary end point, valve thrombosis occurred in 35 of the 364 patients at a median of 2.9 years after implantation. With a total of 2047 patient-years of risk for thrombosis, that event occurred at a rate of $1.7 \%$ per patient-year. The secondary outcome of reoperation occurred in 20 patients at a mean of 7.6 years after initial implant. Freedom from reoperation was $97 \%$ at 5 years, $91 \%$ at 10 years, and $81 \%$ at 15 years. Deaths occurred in 31 patients: 7 operative, 15 cardiac related, and 9 of unknown cause. One of the cardiac deaths was due to pulmonary hemorrhage, but there were no deaths due to valve thrombosis. A time-related competing risk analysis is provided in Figure 3 of Pragt and colleagues ${ }^{11}$ article. The secondary analysis of thrombolysis indicated that when valvar thrombosis was discovered, thrombolysis was effective in more than $80 \%$ of cases.

The strengths of the study by Pragt and colleagues ${ }^{1}$ pertain primarily to its size, time-related end points, and extended follow-up. Its weaknesses are acknowledged in its substantial list of limitations. Retrospectively examining data from 7 different institutions spread over the world will unavoidably miss some important and possibly pertinent information. Although valve thrombosis was the major focus of the study, the incidence of significant bleeding events was not assessed. Although we may accept the authors' explanation for not registering these events, the absence of that information diminishes their message. In addition, these same institutions undoubtedly had surgeons who implanted bioprostheses in the pulmonary position over the same time periods. A comparison of time-related events between bioprosthetic and mechanical pulmonary valve implants at those institutions would have been especially valuable to those of us trying to decide how to include mechanical valves in our pulmonary valve replacement repertoire.

So how do we interpret the findings in this study? As one who was biased against placing a mechanical valve in the pulmonary position, I was surprised that the incidence of valve thrombosis was only $1.7 \%$ per year. The authors ${ }^{1}$ acknowledge that this incidence is higher than what is reported for the aortic and mitral positions, but $1.7 \%$ is lower than I would have predicted. I was also impressed that when thrombosis was diagnosed, it was successfully treated with thrombolysis in the majority of cases. Both of these findings incline me toward considering a mechanical valve in an occasional "selected" case. The cynic in me, however, makes me worry about those 9 deaths for whom the cause was unknown. Could they have died of acute valvar thrombosis? The absence of any cases in this study that come close to such an outcome would argue against that possibility, but we cannot know for sure. Nevertheless, I can understand that there are patients for whom a reoperation would be particularly challenging or are already committed to lifelong warfarin anticoagulation for another valve or condition. The information provided in this study reassures me that a mechanical valve would be a reasonable choice for pulmonary valve implantation in such a patient. But this brings us back to the more typical patient who does not have a contraindication to anticoagulation. In my discussions with that patient, will I offer a mechanical valve as an acceptable alternative to a bioprosthesis? 
As this renewed interest in mechanical valves in the pulmonary position has been going on, the bioprosthetic option has been evolving. Nonmechanical valves implanted in the pulmonary position include aortic and pulmonary allografts, stented and stentless porcine valves, stented pericardial valves, bovine jugular vein valves, and a variety of hand-sewn polytetrafluoroethylene leaflets and conduits. It is accepted that regardless of which nonmechanical valve is implanted, a reintervention or reoperation will be required at some time in the future. In Table 4 of the article by Pragt and colleagues, ${ }^{1}$ data are provided from recent publications on bioprosthetic implants in the pulmonary position. All types appear to function well for 5 years. Freedom from reintervention at 15 years, however, ranged from $41 \%$ to $75 \%$ in the 3 studies with the longest follow-up. $^{20-22}$ An $81 \%$ freedom from reoperation at 15 years in the study by Pragt and colleagues ${ }^{1}$ places mechanical valve implantation in a comparably favorable position. However, reintervention in a patient with a bioprosthesis may be catheter based, whereas the reintervention for a mechanical valve must be a reoperation. Moreover, the catheter-based procedure for the bioprosthesis may be the insertion of a new bioprosthesis within the old one. $^{23,24}$ Progress in catheter-based techniques has now reached the point that a valve can be implanted in the native right ventricular outflow tract in some patients without any operative intervention. ${ }^{25}$ Thus, as percutaneous valve implantation techniques are being successfully applied to the aortic position, similar progress is occurring for the pulmonary position.

Of course, there will always be cases requiring pulmonary valve implantation that can only be addressed surgically. The data from Pragt and colleagues ${ }^{1}$ should rebalance any bias we have had against mechanical valves in the pulmonary position. In patients whose next operation is likely to be risky, there should be little hesitation to implant a mechanical valve. Of course, when warfarin is required for another reason, a mechanical valve also is appropriate. The bigger question relates to the first pulmonary valve implantation in the more typical adult patient. If it cannot be done with a catheter, is a bioprosthesis the only surgical choice or should we include a mechanical valve as an option when we discuss the surgery with the patient? Up until now, I have routinely placed a bioprosthesis. Only rarely did the patient ask about a mechanical valve, and in such a case I used to strongly recommend against it. After reviewing this article, I have decided to start going over both options with the patient. I suspect that most will still prefer that I implant a tissue valve, but we shall see.

\section{References}

1. Pragt H, van Melle J, Javadikasgari H, Man Seo D, Stulak J, Knez I, et al. Mechanical valves in the pulmonary position: an international retrospective analysis. J Thorac Cardiovasc Surg. 2017;154:1368-70.
2. Ross DN, Somerville J. Correction of pulmonary atresia with a homograft aortic valve. Lancet. 1966;288:1446-7.

3. McGoon DC, Rastelli GC, Wallace RB. Discontinuity between right ventricle and pulmonary artery: surgical treatment. Ann Surg. 1970;172:680-9.

4. Cartmill T, Celermajer J, Stuckey D, Bowdler J, Johnson D, Hawker R. Use of Bjork-shiley tilting disc prosthesis in valved conduits for right ventricular outflow reconstruction. Br Heart J. 1974;36:1106-8.

5. Misbach G, Turley K, Ebert P. Pulmonary valve replacement for regurgitation after repair of tetralogy of Fallot. Ann Thorac Surg. 1983; 36:684-91.

6. Ilbawi MN, Lockhart CG, Idriss FS, DeLeon SY, Muster AJ, Duffy E, et al. Experience with St. Jude medical valve prosthesis in children. J Thorac Cardiovasc Surg. 1987:93:73-9.

7. Miyamura H, Kanazawa H, Hayashi J, Eguchi S. Thrombosed St. Jude Medical valve prosthesis in the right side of the heart in patients with tetralogy of Fallot. J Thorac Cardiovasc Surg. 1987;94:148-50.

8. Rosti L, Murzi B, Colli A, Festa P, Redaelli S, Havelova L, et al. Mechanical valves in the pulmonary position: a reappraisal. J Thorac Cardiovasc Surg. 1998;115:1074-9.

9. Haas F, Schreiber C, Horer J, Kostolny M, Holper K, Lange R. Is there a role for mechanical valved conduits in the pulmonary position? Ann Thorac Surg. 2005; 79:1662-8.

10. Dearani J. Invited Commentary. Ann Thorac Surg. 2005;79:1667-8.

11. Waterbolk TW, Hoendermis ES, den Hamer IJ, Ebels T. Pulmonary valve replacement with a mechanical prosthesis. Promising results of 28 procedures in patients with congenital heart disease. Eur J Cardiothorac Surg. 2006;30: 28-34.

12. Horer J, Vogt M, Stierle U, Cleuziou J, Prodan Z, Schreiber C, Lange R. A comparative study of mechanical and homograft prostheses in pulmonary position. Ann Thorac Surg. 2009;88:1534-40.

13. Stulak J, Dearani J, Burkhart H, Connolly H, Warnes C, Suri R, Schaff H. The increasing use of mechanical pulmonary valve replacement over a 40 year period. Ann Thorac Surg. 2010;90:2009-15.

14. Ovcina I, Knez I, Curcic P, Ozkan S, Nagel B, Sorantin E, et al. Pulmonary valve replacement with mechanical prostheses in re-do Fallot patients. Interact Cardiovascular Thorac Surg. 2011;12:987-92.

15. Dos L, Munoz-Guijose C, Mendez A, Ginel AB, Montiel J, Padro JM, Subirana MT. Long term outcome of mechanical valve prosthesis in the pulmonary position. Int J Cardiol. 2011;150:173-6.

16. Shin H, Kim Y, Ko J, Park I, Man Seo D. Outcomes of mechanical valves in the pulmonic position in patients with congenital heart disease over a 20 year period. Ann Thorac Surg. 2013;95:1367-72.

17. Dehaki M, Ghavidel A, Omrani G, Javadikasgari H. Long term outcome of mechanical pulmonary valve replacement in 121 patients with congenital heart disease. Thorac Cardiovasc Surg. 2015;63:367-72.

18. Freling H, van Slooten Y, van Melle J, Ebels T, Hoendermis E, Berger R, et al. Pulmonary valve replacement: twenty-six years of experience with mechanical valvar prostheses. Ann Thorac Surg. 2015;99:905-10.

19. Dunne B, Xiao A, Litton E, Andrews D. Mechanical prostheses for right ventricular outflow tract reconstruction: a systematic review and meta-analysis. Ann Thorac Surg. 2015;99:1841-7.

20. Oliver JM, Garcia-Hamilton D, Gonzalez AE, Ruiz-Cantador J, SanchezRecalde A, Polo M, Aroca A. Risk factors for prosthetic pulmonary valve failure in patients with congenital heart disease. Am J Cardiol. 2015;116: 1252-6.

21. Rotes A, Eidem B, Connolly H, Bonnichsen C, Rosedahl J, Schaff H, et al. Longterm follow-up after pulmonary valve replacement in repaired tetralogy of Fallot. Am J Cardiol. 2014;114:901-8.

22. van de Woestijne PC, Mokhles MM, de Jong PL, Witsenburg M, Takkenberg JJM, Bogers A. Right ventricular outflow tract reconstruction with an allograft conduit in patients after tetralogy of Fallot correction: long-term follow-up. Ann Thorac Surg. 2011;92:161-6.

23. McElhinney D, Hellenbrand W, Zahn E, Jones T, Cheatham J, Lock J, Vincent J. Short-and medium-term outcomes after Transcatheter pulmonary valve placement in the expanded multicenter us melody valve trial. Circulation. 2010; 122:507-16.

24. Wilson W, Benson L, Osten M, Shah A, Horlick E. Transcatheter pulmonary valve replacement with Edwards Sapien system. JACC: Cardiovascular Interventions. 2015:8:1819-27.

25. Jalal Z, Thambo J, Boudjemline Y. The future of transcatheter pulmonary valvulation. Arch Cardiovasc Dis. 2014;107:635-42. 